\title{
Immunization Campaigns: Mitigating Barriers - Designing Communication ${ }^{1}$
}

\author{
Deepak Gupta \\ Strategic Communication Programmes -UN system in Asia and the Pacific Regions - drguptad11@gmail.com \\ Badrul Hassan
}

UN Programme Specialist - badrulsocial@gmail.com

Anusha Agarwal

Indian Institute of Management, Lucknow - anusha.agarwal@iiml.org

Avni Bhasin

Management Development Institute, Gurugram - pg18avni_b@mdi.ac.in

\begin{abstract}
This paper revisits varied conceptual frameworks of the strategic communication, especially applicable on vaccination challenges that the immunization programmes are confronted with world over and how critical it is to ensure addressing the 'last mile' gaps in attaining cent percent vaccination coverage. It is based on consolidated reflections gathered together through varied field experiences and study of programme approaches. It assumes further significance as ensuring social-inclusion of vulnerable, hard-to-reach and poor populace is the key to using strategic communication as a marketing communication approach in bringing about positive behaviour change in the communities. Across the

been struggling for many decades in reaching out to communities and delivering the vaccination programmes. Despite the efforts invested in by the respective governments on supply aspects of vaccinations, social scientists continue to face challenges with the demand generation dimensions of the immunization programmes. Therefore, a significant emphasis on the "health seeking behavior' aspects in individuals and their respective communities play a significant role in achieving cent percent immunization coverage. The current paper propounds a model called Vaccination Communication Model, i.e. 'VCM' which provides a modular approach in facilitating design of its immunization communication strategy.
\end{abstract} world, the public health programmes have

Keywords: Vaccination barriers, Strategic Health Communication, Vaccination communication model, Social inclusion.

1 Authors have dedicated this work to the International Immunization Week of 2019 that is observed in the last week of April. 


\title{
Campanhas de Imunização: Mitigando Barreiras - Projetando a Comunicação
}

\begin{abstract}
Sumário
Este texto revisita as diversas estruturas conceituais da comunicação estratégica, especialmente aplicáveis aos desafios da vacinação, com os quais os programas de imunização são confrontados em todo o mundo, salientando como é importante assegurar a abordagem das lacunas do "quilómetro final" na obtenção da cobertura de cem por cento de vacinação. $\mathrm{O}$ ensaio baseia-se em reflexões consolidadas reunidas através de experiências de campo variadas e estudo de abordagens de programas. Assume ainda mais importância, pois garantir a inclusão social de populações vulneráveis, difíceis de alcançar e pobres, é a chave para usar a comunicação estratégica como uma abordagem de comunicação de marketing, de forma a promover mudanças positivas no comportamento nas

gramas de saúde pública têm lutado, ao longo de muitas décadas, para chegar às comunidades e realizar os programas de vacinação. Apesar dos esforços investidos pelos respetivos governos no fornecimento de vacinas, os cientistas sociais continuam a enfrentar desafios com as dimensões de gestão da procura dos programas de imunização. Assim, uma ênfase significativa nos aspetos do "comportamento de busca da saúde" nos indivíduos e nas respetivas comunidades desempenha um papel significativo na obtenção de uma cobertura de cem por cento de imunização. O presente ensaio propõe um modelo designado Vaccination Communication Model, ou seja "VCM", que fornece uma abordagem modular para facilitar o desenho da estratégia de comunicação de imunização.
\end{abstract} comunidades. Em todo o mundo, os pro-

\footnotetext{
Palavras-chave: Barreiras na vacinação, Comunicação estratégica em saúde, Modelo de comunicação de vacinação, Inclusão social.
}

The key strategies in ensuring child survival, both in mitigating morbidities and mortalities, include adherence to the immunization schedule. Across the world, the public health programmes have been struggling for many decades in reaching out to communities and delivering the vaccination programmes. Despite the efforts invested in by the respective governments on supply aspects of vaccinations, social sci- 
entists continue to face challenges with the demand generation dimensions of the immunization programmes. Therefore, a significant emphasis on the 'health seeking behavior' aspects in individuals and their respective communities play a critical role in achieving cent percent immunization coverage.

Globally, the national immunization programmes are confronted with varied challenges. These include multiple issues related to the supply aspects and equally critical concerns focusing on the demand side. Ensuring sustainable demand for immunization is only possible when caregivers and communities trust the safety and efficacy of vaccines, as well as the quality and reliability of immunization services. They also need to have the necessary information, access and motivation to complete the recommended immunization schedule on time. A select few demand aspects of the immunization that include, but not limited to, are: resistance, reluctance, trust and belief in vaccine-efficacy and vaccine-hesitancy. Vaccine hesitancy and lack of access to vaccination, for varied reasons and in different settings, is an important issue that requires urgent attention. This is more so due to the risk of decrease of vaccination coverage and consequent control of preventable diseases. Though it is not considered a specific determinant, yet weak or inadequate communication can contribute to a great extent, to vaccine hesitancy and thus negatively influence vaccination uptake.

The aim of the current Vaccination-Communication-Model (VCM), as propounded in this paper, is to present to the broader audiences, i.e. international public health and development managers an overarching approach, proposing the identification of the lead actions that should be taken into account and prioritized in order to improve strategic communication in the domain of immunization campaigns. Communication and community-centered behaviour change are the integral parts of social science, which can be applied in varied ways entirely depending on specific programme needs, structure and spread of communities, wide expanse of networks and the political and economic realities of a given country. There are a number of standardized guidelines and approaches available for using in communication for immunization, yet there is no one-size-fits-all communication strategy that can truly bring about the real positive change in attaining the immunization success. Hence, the current vaccination communication model (VCM) explores a number of associated risk-factors and proximate/s, which if addressed through 'enablers' shall facilitate designing appropriate strategic communication interventions to foster strengthened immunization. 


\section{IMMUNIZATION | CONTEXT}

Global vaccination coverage remains at $85 \%$, with no significant changes occurring in the past several years; it rather deteriorated in recent years. A total of 124 countries reported diphtheria, pertussis, and tetanus (DPT) vaccine coverage rates of $90 \%$ or greater in 2017, which was 135 countries in 2012. By the end of 2017, $85 \%$ of children received one dose of measles vaccine by their second birthday, and 167 countries had included a second dose as part of routine immunization and $67 \%$ of children received two doses of measles vaccine according to national immunization schedules. It is also reported that the number of measles cases are rapidly increasing in the USA and many other western countries. According to CDC (USA), there were 372 measles cases reported in 2018. A considerable large size of populations continues to pose a major challenge as they suffer from limited access to immunization services. Such a gap in immunization coverage amongst well and poorly performing countries is only widening on an annual basis. Studies indicate that millions of children were not protected against diphtheria, pertussis, and tetanus diseases. As it is evident, polio continue to be endemic in three countries (Afghanistan, Pakistan and Nigeria), while the newer vaccines still throw a challenge of low uptake in many regions across the world. A complete lack of or poor access to health facilities and vaccination programmes, insufficient and inappropriate use of available resources, poor technical capacity and least empowered immunization decision-making bodies (such as National Immunization Technical Advisory Group), lack of political will, civil conflict and war, and natural disasters - all of these risks contribute to under-immunization.

Targeting smallpox was the very first vaccine, which was discovered and came into use in the late 1700s and early 1800 . Yet, it was not until almost two centuries later that immunization services began to reach majority of the children in low- and middle-income countries (LMICs). In the year 1974, World Health Organization (WHO) and UNICEF proposed the Expanded Program on Immunization (EPI) with the goal of universal coverage by the year 1990. As per the documented studies, by the year 2012, an estimated 2.5 million deaths were averted each year by vaccination. However, nearly 1.5 million children still die from the diseases preventable by vaccines recommended by the WHO (2012). About $29 \%$ of deaths in children 1-59 months were vaccine preventable in 2012. And in the year 2019, the world will be marking the completion of 45 years of the EPI; it is 
the time perhaps to step back, reflect, deliberate and urgently take appropriate actions to ensure that the benefits of available vaccines reach to all the eligible children and that all the caregivers are positively engaged with addressing child morbidity and mortality through vaccine preventable diseases. Therefore, reaching out, engaging, knowledge-sharing, persuading with evidence, enabling and empowering communities to practice adherence to immunization for all children is a significant common denominator to every national immunization programme, including the immunization programmes confronted with the last-mile coverage challenges.

\section{EVOLUTION OF HEALTH COMMUNICATION | PERSPECTIVE: COMMUNICATING IMMUNIZATION}

With much of the field-research documented in the social and behaviour change communication (SBCC) for health, especially routine immunization in many developing countries, it is found that the social mobilization and community based communication has witnessed broader shifts in its conceptual and theoretical approach over a period of time (IEC $>>$ Programme Communication $>>$ Health Promotion/Education $>>$ SBCC). Therefore, integral to programme design is strategic amalgamation of meeting the information and communication needs of marginalized, hard-toreach and vulnerable people, especially in integrating them with the empowerment process, while the intended communities evolve to a more positive behavior-change for health practice.

Communication strategies, especially targeting immunization programmes in addressing the sustained behavior-change interventions shall work on the premise of a paradigm called 'Another Development'. It is within communities that the reality of development is experienced, thus community participation in the design and implementation of health \& development programmes remains an essential element to the positive change process. Alternative communication (local \& community-owned) systems and media practices are therefore, regarded as significant means for local people to engage in health \& development activities, and as a two-way process in which communities can participate as key change-agents in evolving to a more positive behaviour practice. Inherent to the paradigm is an increased priority to horizontal, multi-directional communication methods that utilize a mix of channels and 
emphasize the importance of two-way communication through sustained dialogue in facilitating trust and mutual understanding, which provide adequate space to the voice of socially-excluded and disempowered people and empower them to identify ways of overcoming the targeted problems in order to improve their own health and well-being.

In fostering a sustained social and behaviour change communication interventions in communities, within the gamut of development and health programmes, the proponents of various communication theories and frameworks have cited how social change takes place and how a positive and progressive change is communicated through select communication channels over a period of time to individuals, communities and society. Integrated within the immunization programmes, a few select conceptual frameworks are recommended to be employed.

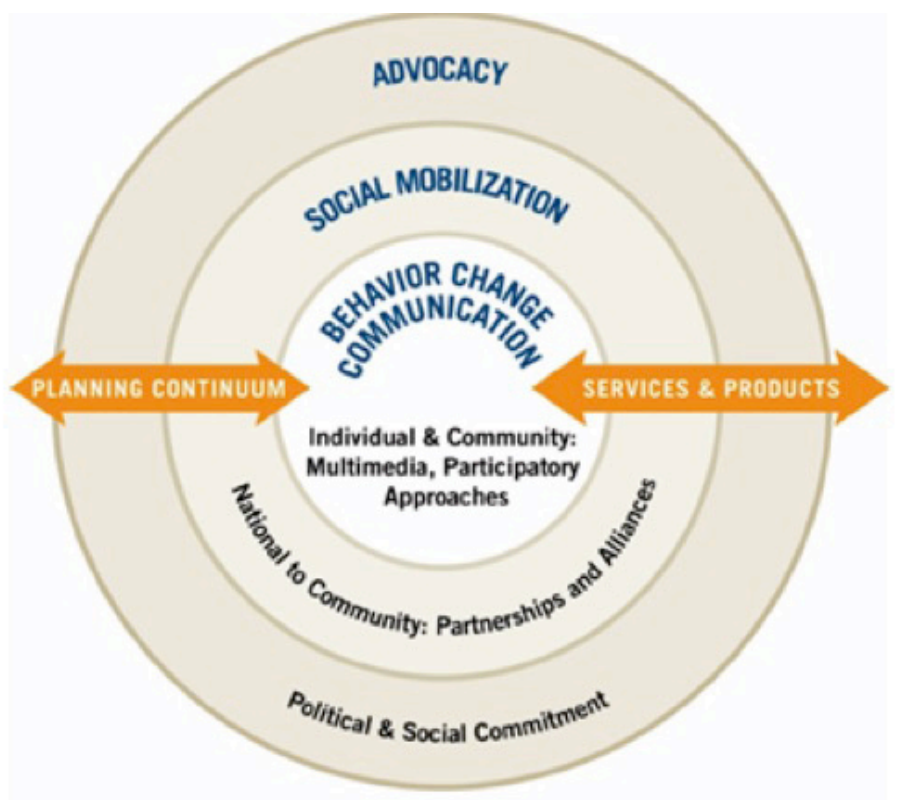

Figure 1. Socio-Ecological Model in the Communication for Health \& Development paradigm. Source: Adapted from Mckee, N. Social Mobilization and Social Marketing Development Communities (1992). 
A set of recommended interventions under the vaccines' communication strategy, if technically assessed at various proposed stages of their evolution, will employ four primary theoretical conceptual frameworks in strategic health communication, namely: Theory of Diffusion of Innovations (Evert M. Rogers); the Theory of Planned Behaviour (Icek Ajzen); Stages of Change Theory (Prochaska DiClemente \& Norcross) and; Health Belief Model (Hochbaum \& Rosenstock).

SBCC expands BCC, explicitly recognizing the importance of changing social norms and increasing social support for behaviour change, and acknowledging that change at the individual level occurs within the concentric circles of influence of family, community and society. This dynamic inter-relationship between individual, family, community and society is also well illustrated through the Socio-Ecological Model (Figure 1) in the Communication for Health \& Development paradigm. It is noteworthy that while approaching Child Survival (health communication), whether increasing vaccination services access, motivating for breastfeeding adherence, fostering hygiene \& sanitation behaviors, and even maternal health care services, socioecological model stands its ground.

All the successful social \& behaviour change communication interventions are built on an understanding of the complex social, cultural and economic factors that make up the multiple levels of determinants of health and health behavior. Two complementary (and sometimes overlapping) health communication theories are used in designing behaviour change interventions: explanatory or predictive theories, which examine why a particular behaviour occurs; and change theories, which focus on how behaviors can be changed (Schmidt, 2014). Explanatory models are essential for guiding the formative steps of designing a behaviour change communication intervention: Without a clear understanding of why people perform or don't perform a particular behavior, interventions are not likely to succeed. This also signifies the inherent need for integrating qualitative and formative research into any SBCC design and interventions, which essentially bring forth the true human-faces behind the hidden statistical data.

These conceptual models are poised to serve as common denominators at various stages of the intended health communication interventions under the immunization programmes.

In the process of behaviour change, the ultimate end result is also gauged with the number of change-catalysts termed as advocacy-agents, who in turn serve as positive deviants in a given community. These are converted advocates of a given health- 
behaviour such as adhering to a complete prescribed vaccination schedule as they not only practice it but also serve as positive examples in a given community. The concept of positive deviance was further refined and consolidated by Jerry Sternin (Tufts University, Boston, USA). It demonstrated how positive behaviour by a few individuals in the community (called Positive Deviants- PD) who do things differently or practice healthy behaviors as compared to others in the community can eventually lead to far-reaching positive changes within the community. More often than not, caregivers practicing complete vaccination - who have successfully undergone the complete cycle of routine immunization for their children and have emerged as 'Child Health champions' - can serve as the forceful advocates of the immunization programme. Such 'catalysts' (positive change-agents) invariably encourage rest of the community in promoting reaching out to the health facility/vaccinators, seeking immunization facilities and adhering to its complete course. PD offers a systematic framework to identify assets, indigenous knowledge, and home-grown solutions, and to amplify them for wider adoption.

Out of various available media approaches, integrated approach (a strategic mix of mass media and interpersonal communication) is largely proposed as integral to the immunization communication strategies as a sustained approach to reach out to, engage with, educate and foster positive change (Figure 2). Such a campaign design will draw strategic advantage from and thus, combine a strong presence of mass-media for awareness and branding and strategic use of interpersonal and extension approach in reaching out to individual households and caregivers in the communities; thus, engaging with individuals and communities in bringing about a positive behaviour change for promoting vaccination.

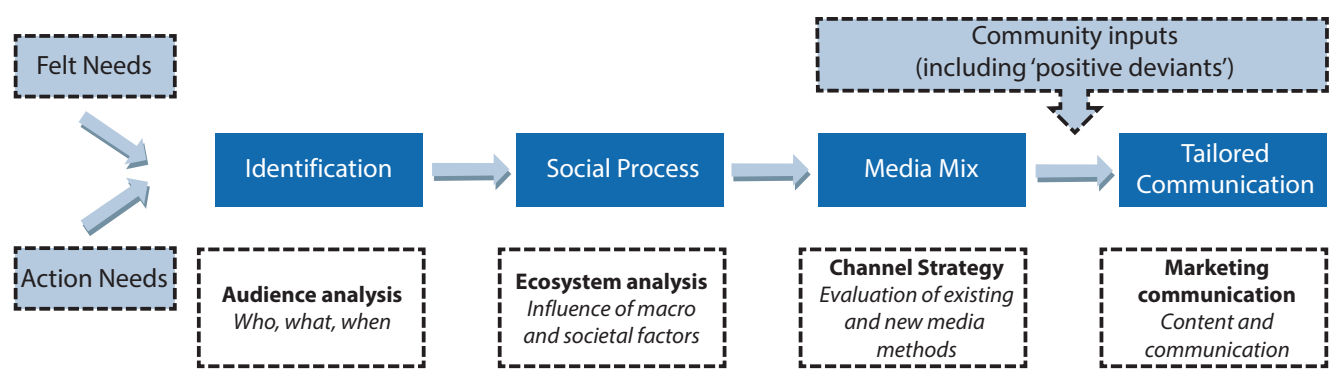

Figure 2. Integrated Communication Approach. 
Translating and effectively converting technical-information and complex sociobehavioral messages into creative, appealing and acceptable approaches that trigger sustained dialogue among participants is often one of the most difficult and daunting tasks within the design and delivery of SBCC initiatives for immunization campaigns. Therefore, the immunization campaign needs to take into account, as its starting point, both the 'felt needs' at community or local level, and the 'action needs' as to be identified through risk-factors analysis. The operational immunization campaign strategy for meeting these two sets of needs shall ideally follow four stages of activities.

The first stage is identifying and analyzing the innovations sought by the community and those that the programme goal desire to introduce to whom, when and with what material means. This is generally known as the diffusion stage in the conceptual framework of development or strategic health communication.

At the second stage, which is also known as the social process stage, the fulcrum of activities is towards determining how existing social, cultural, psychological and indigenous communication factors, as well as government organizational factors, would help or hinder the adoption of (or adherence to) new practices and behaviors among the groups of people targeted under the EPI campaign.

In the third stage, all efforts are put together towards identifying available media at the field level and how they relate with the people; wherein it must include hardto-reach and vulnerable populace. At this stage, campaign team should look at what best combination of communication channels exist and how they can be used in the communities most effectively - that includes traditional and interpersonal channels, as well as modern print and electronic media - for communication 'feed' both into and from the community.

And in the final stage, locally tailored communication interventions shall be drawn and implemented in phases with the real action potential in the communities. This process will indeed be taking into account available supplementary inputs from outside the community, which are positioned to compliment the strategic process of SBCC for sustained practice of Routine Immunization.

Considering the stratified and multi-layered immunization campaign design, the relevant SBCC strategy for the immunization interventions should consider positioning the following approach (Figure 3 ) in ensuring reaching all individuals and communities in respective countries with the mandate of equity: 


\section{Actionable SBCC Interventions: Central, Provincial/Divisional, District, Village/Community \& Individual Levels}
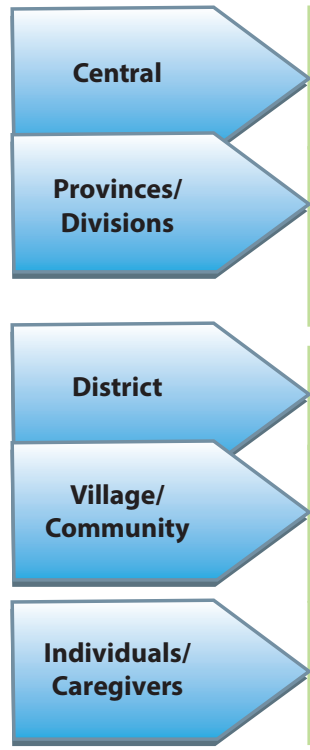

Achieve consensus on Immunization Campaign Goal (including SBCC objectives) and to support health and communication sectors in delivery of vaccination messages (progressive policy, enabling environment, and adequate resources)

Engage, plan, inform, and support health/vaccination officials and stakeholders in managing and delivering high quality vaccination campaign messages (advocacy, capacity building, communication material and logistics resources)

To engage, inform, build capacities, and support health officials in managing and delivering high quality focused and accurate vaccination messages

Disseminate, on a sustained basis, the key vaccination messages and facilitate families/community members' comprehension of the same to promote health seeking behaviors

Ensure reaching out primary messages, build knowledge-base \& required skills, dispel myths through sustained efforts and interpersonal communication and address vulnerabilities by reaching quality vaccination services

Figure 3. Actionable SBCC Interventions.

Despite the success of routine childhood immunization programmes in reducing the incidence of vaccine-preventable diseases (VPDs), immunization uptake varies among countries across the world, including among various ethnic and vulnerable groups. As the research demonstrates, there are also vast recorded differences in the coverage between the different scheduled vaccines. Inequity in uptake of routine vaccines has contributed to an accumulation of susceptible individuals in several countries across the globe; hence, also to the continued occurrence and spread of some vaccine-preventable diseases.

Addressing Inequities - Inequities in health are associated with the social determinants of health; furthermore the inequities in the immunization strategies are also related to the concepts of social justice, fairness and ethics. 
Inequity in immunization: Avoidable differences in immunization coverage between population groups that arise because barriers to immunization among disadvantaged groups are not addressed through policies, structures, governance or programme implementation

Equitable access to vaccines: All individuals are offered the same vaccines through delivery services that are tailored to meet their needs

Social determinants of health: The underlying conditions in which people are born, grow, live, work and age. These determinants include parental income, education, living standards, gender equity, distribution of power, policy frameworks and social values, thus directly bearing its impact on healthbehaviors.

It is important to acknowledge that immunization coverage may be affected by social determinants and it is a critical factor in addressing those differences in uptake that arise from inequity in vaccine delivery and access. Generating adequate demand (re: health seeking behavior) in communities, especially in ensuring strategic communication outreach to vulnerable, hard-to-reach and socially excluded populace is an equally critical investment, while the strengthened system of vaccine delivery and logistics continue to play a pivotal role.

In the global context, the usual process of designing a SBCC strategy in fostering strengthened EPI further consolidate the prevailing perception that there is a clear need to move beyond measuring the difference between worst and best-performing geographical areas and to accurately identify who or which groups are not being immunized and where (and why). The much needed and inherent process of risk-factors' analysis and community-level consultations facilitates participatory approach therefore, it further strengthens the campaign-design process in choosing the most appropriate communication-tools, strategic messages and the linked interventions for vulnerable and the hard-to-reach populace. This process also ascertains the mandate of equity and social inclusion through strategic communication in support of immunization. The process of addressing respective barriers, which individuals and community face, and thus empowering them through 'enablers', is the key to achieving the vaccination success. 


\section{IMMUNIZATION CAMPAIGN: MITIGATING PRIMARY BARRIERS IN DESIGNING STRATEGIC COMMUNICATION INTERVENTIONS}

\begin{tabular}{|c|c|c|}
\hline $\begin{array}{c}\text { Barriers } \\
\text { ['Risk factors'] }\end{array}$ & $\begin{array}{c}\text { Enablers } \\
{[\text { Proximate Determinant }(\mathrm{s})]}\end{array}$ & $\begin{array}{c}\text { Strategic Communication } \\
\text { Actions }\end{array}$ \\
\hline $\begin{array}{l}\text { Caregivers/families, due to } \\
\text { poverty, cannot afford a health } \\
\text { service, such as vaccinations for } \\
\text { their children }\end{array}$ & $\begin{array}{l}\text { Poverty alleviation strategies } \\
\text { mitigate drudgery of people and } \\
\text { foster economically empowering } \\
\text { initiatives; } \\
\text { Vaccination services are made } \\
\text { free to all the individuals. }\end{array}$ & $\begin{array}{l}\text { Empowering caregivers with } \\
\text { free access to safe and quality } \\
\text { vaccination services at the door- } \\
\text { step through knowledge, skills } \\
\text { and enhanced access }\end{array}$ \\
\hline $\begin{array}{l}\text { Illiteracy and lack of knowledge } \\
\text { about benefits of completed } \\
\text { immunization for child survival }\end{array}$ & $\begin{array}{l}\text { People are ensured to have } \\
\text { access to affordable and } \\
\text { quality education for all and } \\
\text { provided with the 'quality of life' } \\
\text { knowledge and skills, including } \\
\text { health \& hygiene knowledge }\end{array}$ & $\begin{array}{l}\text { Fostering sustained engagement } \\
\text { with caregivers and community } \\
\text { leaders in imparting necessary } \\
\text { knowledge \& skills to practice } \\
\text { adhered vaccination schedule }\end{array}$ \\
\hline $\begin{array}{l}\text { Misconceptions and rumors } \\
\text { restrict caregivers from } \\
\text { practicing routine immunization } \\
\text { for their children }\end{array}$ & $\begin{array}{l}\text { All the misconceptions \& } \\
\text { associated rumors are timely } \\
\text { intercepted and mitigated by the } \\
\text { credible sources such as, Health } \\
\text { Professionals, Faith Leaders and } \\
\text { sustained Media discussions }\end{array}$ & $\begin{array}{l}\text { Ensuring health providers' } \\
\text { sustained engagement with } \\
\text { caregivers and community } \\
\text { leaders in imparting necessary } \\
\text { knowledge \& skills to practice } \\
\text { vaccination and also promote } \\
\text { continued positive media } \\
\text { coverage, thus removing all } \\
\text { possible misconceptions and } \\
\text { addressing rumors. }\end{array}$ \\
\hline $\begin{array}{l}\text { Hard-to-reach, geographically } \\
\text { vulnerable populace and } \\
\text { constantly on-the-move/ } \\
\text { migratory populations are } \\
\text { devoid of accessing vaccination } \\
\text { services }\end{array}$ & $\begin{array}{l}\text { Respective governments and } \\
\text { local administrations make sure } \\
\text { that all the vaccination services } \\
\text { are targeted with 'equity', i.e. } \\
\text { reaching the unreached and } \\
\text { vulnerable. }\end{array}$ & $\begin{array}{l}\text { Advocating with government } \\
\text { to strengthen immunization } \\
\text { services and persuasive } \\
\text { messages reaching hard-to- } \\
\text { reach, ethnic/indigenous } \\
\text { communities and vulnerable } \\
\text { populations, including } \\
\text { ensuring quality accessibility to } \\
\text { vaccination schedules for mobile } \\
\text { populations }\end{array}$ \\
\hline
\end{tabular}




\section{Immunization Campaigns: Mitigating Barriers - Designing Communication}

\section{Barriers ['Risk factors'] $7 \begin{gathered}\text { Enablers } \\ {[\text { Proximate Determinant(s) }]}\end{gathered} \begin{gathered}\text { Strategic Communication } \\ \text { Actions }\end{gathered}$}

Religious practices or faith leaders discourage or ban the followers from practicing vaccination due to misbelieve or misinformation

Weak health system that is not capable of ensuring logistics, maintenance of appropriate vaccines with cold-chain and reaching out to the communities

Vaccination teams do not have communication/transportation facilities in reaching the communities that are far

\begin{abstract}
All faith leaders are positively engaged with the vaccination programmes and shared scientific knowledge with on immunization issues.
\end{abstract}

Health System Strengthening (HSS) is accorded the highest priority by the respective governments and planners.
Effectively mitigating misinformation on vaccinations through evidence-based advocacy with faith leaders' alliance

Sustained and evidence-driven advocacy with the senior political leadership and policy makers to strengthen the health systems in a given country

Governments ensure that appropriate and timely transportation is provided to the vaccination teams and that the providers are well equipped with the required communication aids.

Immunization managers initiate and regularly organize and thus, ensure that vaccinators are empowered with the newgeneration counseling \& IPC skills

Policy advocacy with national governments fostering development of a business case for vaccine transportation/ communication through community involvement

Facilitate a minimum standard package for vaccine session at any facility to ensure quality of vaccination, counseling, takeaway messages and follow up actions.

Promote, through data-driven advocacy, immunization as an integral part of the national health service delivery system benefitting all children (Support a systematic budget analysis)
National governments ensure adequate resources to facilitate quality vaccination programmes and legislate appropriate bills/ policies.
Health programme does not have sufficient resources in fostering a comprehensive immunization programme (policy, human resources, vaccines, political support)

Practicing health professionals (OB/Gyn, General Practitioners, Traditional Healers, Pharmacies, Health Counselors \& Vaccinators) either do not have knowledge of or do not proactively advice on adherence to vaccinations
Foster partnership model

Private doctors, traditional healers and pharmacy shops are engaged with in communicating benefits of immunization adherence. between public vaccinators and practicing health professionals and pharmacies in order to facilitate motivation for caregivers for ensuring vaccination. 


\section{Barriers \\ ['Risk factors']

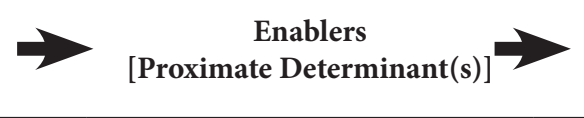 \\ Strategic Communication \\ Actions}

Media does not provide sufficient space to progressive health stories and still worse, create negative opinion on vaccinations by fostering rumors and myths;

AEFI cases create uproar in communities and dissuade caregivers to adhere to vaccination
Sensitive and proactive media houses and health reporters, through regular media discussion, enable to secure better space for immunization stories.

Evidence-based advocacy with media editors and health reporters on vaccination issues strengthen community environment in support of immunization programme;

Early and scientific response to any AEFI cases reported in media is well responded to, through well managed riskcommunication, with correct evidence.

Design and launch, through most appropriate tools, a

Strengthened health

Caregivers do not know the communication with all caregivers ensure complete scientifically researched and benefits, schedule, after effects (if any) and venue/date/time of vaccinations. knowledge on benefits, schedule and date-notification on the immunization community-driven campaign reaching all caregivers with primary messages on adherence to vaccination, date-notification and follow-up.

Advocacy with respective national governments to establish recognition and benefits plan for employers that promote staff wellbeing, including vaccination for employees' children.

Employers do not promote family wellbeing issues and do not facilitate child-vaccinations at work place
All the employers (public \& private sectors) are sensitized to the vaccination priorities of their employees' children

\section{'VCM' | BASED ON MOSLEY \& CHEN THEORY}

The current work on 'Vaccines Communication Model' (Gupta/Hassan/Agarwal/Bhasin), as propounded herein, has its leanings from the earlier research of Mosley and Chen (1984) on proximate theory of social determinants of child morbidity and mortality. Mosley and Chen proposed a conceptual framework for the study of the determinants of child survival, especially in developing countries that incorporated both social and biological variables. The primary feature of the Mosley-Chen 
framework is the due emphasis on a set of proximate determinants that are directly linked with and thus, influence the risk of morbidity and mortality in children. It is noted that all social and economic determinants must operate through the proximate determinants to affect child survival. Therefore, in order to strengthen national immunization programmes, it is of paramount importance to address the surrounding risk-factors that directly restrict or limit the caregivers' accessibility, affordability, ability, knowledge and behaviour from practicing the scheduled vaccination for their children.

\section{STRATEGIC COMMUNICATION IN IMMUNIZATION | A ROAD AHEAD FOR THE LAST-MILE COVERAGE}

Scientifically designed strategic communication interventions in support of immunization programs often focus on generating clients demand. Herein the mass media have also helped mobilize communities in rapidly increasing the vaccination coverage. However, health communication is poised to address more complex issues of long-term sustainability, reaching out to hard-to-reach populace, and in managing certain negative repercussions of high rates, for example, diminishing concerns about the seriousness of disease. This assumes significance especially in the context of countries confronted with addressing the last-mile coverage challenges.

Increasingly, most countries are reporting vaccination data which indicate high access to immunization services (BCG, DPT1, and OPV1 rates) but rather lower complete coverage. And this is due to a large number of dropouts, in other words the 'critical gap' remains in covering the last-mile. Needless to emphasize, these dropouts reflect a problem in one or both of the two given areas, i.e. (i) service barriers (such as missed opportunities to vaccinate); and (ii) consumer barriers (such as lack of access to or understanding of correct information, fear of side effects, or competing belief systems). In many countries immunization managers are realizing that it is more difficult to achieve and sustain the final ten percent or fifteen percent of coverage than it was to achieve the initial targets of 60 percent or even 75 percent. Hence, in each of such cases strategic-communication has a critical role to play. It is clear that the strategic-communication offers feasible strategies for reducing both service and consumer barriers to foster complete coverage and for promoting and sustaining positive immunization behaviour among these groups on a long-term basis. 


\section{Deepak Gupta, Badrul Hassan, Anusha Agarwal, Avni Bhasin}

\section{REFERENCES}

Athar Ansari M., Khan Z., \& Khan I. (2007). Reducing resistance against Polio drops. Perspectives in Public Health-2007-1.

Bergdall, D. (1993). Methods for Active Participation-Experiences in Rural Development from East and Central Africa. Nairobi, Kenya: Oxford University Press.

Berrigan, F. J. (1981). Community Communications: The role of the community media in development. Paris: UNESCO.

Bocquier A., Ward J., Raude J., Peretti-Watel P., \& Verger P. (2017). Socioeconomic differences in childhood vaccination in developed countries: a systematic review of quantitative studies. Expert Rev Vaccines, 16(11), 1107-18.

Canary, Daniel J., Cody, Michael J., \& Manusov, Valerie Lynn. (2008). Interpersonal communication: a goals-based approach (Fourth edition). Bedford/St. Martin's, Boston, MA.

CDC. (2019). National Notifiable Diseases Surveillance System. Measles/rubella 2013 case definition. Atlanta, GA: US Department of Health and Human Services, CDC; 2019 and https://www.cdc.gov/measles/cases-outbreaks.html

Davis, Terry C., \& Kennen, Estela M. (2006). Vaccine Risk/Benefit Communication: Effect of an Educational Package on Public Health Nurses. Health Educ Behav. 33(6), 787-801.

Freire, P. (1970). Pedagogy of the Oppressed. , New York: Continuum/Seabody.

Frederiksen, L. W., Solomon, L. J., \& Brehony, K. A. (1984). Marketing health behavior: Principles, techniques, and applications. New York: Plenum Press.

Fugelsang, A., \& Chandler, D. (1987). Development Communication Case Study: The paradigm of communication in development: From knowledge transfer to community participation-lessons from the Grameen Bank. FAO: Rome.

GAVI. (n.d.). Demand promotion and community engagement, Health System and Immunization Strengthening. Retrieved from https://www.gavi.org/support/ hss/demand-promotion 
Grover, C., \& Grover, I. (1991). Effective Communication of Messages to Rural Women Through Media-Mix. VIDURA, PII, Vol. 28, Issue No. 2.

Gupta, D., Ariyarathne, K., Refai, A., \& Rathnayake, S. (2018). Confronting Health Communication Challenges Addressing Tuberculosis in Sri Lanka: Synopsis. Interações: Sociedade e as Novas Modernidades, (35), 134-147. doi:10.31211/ interacoes.n35.2018.e1

Gupta, D., \& Bansal, K. (2014, July). Strategic Communication in Polio Eradication, Journal: Media Map, ISSN 2349-5944, Issue IV, Volume I, 31-33.

Health Survey Results Unit [MOHFW]. (2010). Publication/Final Version; Evaluation and Intelligence Division, Ministry of Health and Family Welfare, Government of India.

Hettne, Björn (1990). Development theory and the three worlds. New York: Wiley.

Hornik, R. C. (2002). Public health communication: evidence for behavior change. Mahwah, NJ: Lawrence Erlbaum Associates.

Lewin, T., \& Patterson, Z. (2012). Approaches to Development Research Communication. IDS Bulletin, Volume 43, Number 5.

Mason, A. M., \& Wright, K. B. (2014). Department of Communication, George Mason University, Fairfax , Virginia, USA; The Life Cycle of a Virus: The Infectious Disease Narrative of NDM-1, Journal of Health Communication: International Perspectives.

Mayo J., \& Servaes J. (eds.) (1994). Approaches to Development Communication: An Orientation and Resource Kit. UNESCO \& UNFPA.

McCombs, Maxwell E., \& Donald L. Shaw (1993). The evolution of agenda-setting research: Twenty-five years in the marketplace of ideas. Journal of Communication 43, 58-67.

Mosley, W. H., \& Chen, L. C. (1984). An analytical framework for the study of child survival in developing countries. Population and Development Review 1984; 10(Suppl): 25-45. Reprinted in Bull WHO 2003, 81(2), 140-148.

Robert Hornik (ed.) (2001). Public Health Communication: Evidence for Behaviour Change. NJ, USA: Lawrence Erlbaum Associates, Inc. Publishers. 
Schiavo, Renata (2007). Health communication: From theory to practice. San Francisco: Jossey-Bass

Shmidt, K. (2014). Applying Lessons from Behavior Change Communications to the Design of an Intervention Promoting Family and Community Support for Learn-ing to Read. Education Data for Decision Making (EdData II), Task Order 20. Report. RTI International. Retrieved from https://www.globalreadingnetwork.net/eddata/applying-lessons-behavior-change-communicationsdesign-intervention-promoting-family-and

Schulz, Peter J. (ed.) (2010). Communication Theory, 4 vols. Thousand Oaks, CA: SAGE.

Shimp, L. (2004). Strengthening Immunization Programmes: Communication Component. Arlington, Virginia, Partnership for Child Health Care, Basic Support for Institutionalizing Child Survival (BASICS).

Singhal, A., Buscell, P., \& Lindberg, C. (2010). Inviting everyone: Healing healthcare through positive deviance. Bordentown, NJ: Plexus Press.

The World Bank. (2003). Strategic Communication for Development Projects: A toolkit for task team leaders. Washington, D.C.

World Health Organization. (2017). Immunization Coverage - Facts/Coverage 2017. Retrieved from https://www.who.int/news-room/fact-sheets/detail/ immunization-coverage

World Health Organization. (2013). Global routine Vaccination Coverage, 2012. Weekly Epidemiological Rec., 88, 482-5.

Wright, Kevin B., Sparks, L., \& O'Hair, H. D. (2008). Health communication in the 21st century. Malden, MA: Wiley-Blackwell. 